\title{
The Resilience Scale: A Duplication Study in Japan
}

\author{
Chieko Hasui $^{1, \S}$, Hiromi Igarashi ${ }^{1, \S}$, Noriko Shikai ${ }^{1, \S}$, Masahiro Shono ${ }^{2, \S}$, Toshiaki Nagata ${ }^{3, \S}$ and \\ Toshinori Kitamura ${ }^{*}, 1$,
}

\author{
${ }^{1}$ Kumamoto University Graduate School of Medical Sciences, Japan \\ ${ }^{2}$ Yuge Hospital, Japan \\ ${ }^{3}$ Kyushu University of Nursing and Social Welfare, Japan
}

\begin{abstract}
To examine the factor structure, construct, and predictive validity of the Resilience Scale (RS), Japanese university students $(\mathrm{N}=504$ to 547$)$ were examined. The RS has a good internal consistency and a single factor structure. Students high in resilience were less likely to be depressed or suicidal; more likely to adopt task-oriented coping but less likely to adopt emotion-oriented coping; more likely to have secure attachment with an opposite-sex partner; less likely to have shame feeling but more likely to have pride feeling; more likely to show healthy narcissistic personality traits but less likely to show identity diffusion; more likely to report their parents as high in care and low in overprotection; and more likely to report receiving punishment as a child. The RS is shown to be a significant predictor of the depressive severity two weeks later after controlling for demographic variables, baseline depression, and negative life events, which occurred during the previous week. Thus, the RS is a valid measure in a Japanese student population.
\end{abstract}

\section{INTRODUCTION}

In the 1970s the focus of research in social psychology and psychiatry shifted from personal attributes of people who developed psychological maladjustment, including psychiatric disorders, to the personal attributes that protect people from developing such maladjustments when exposed to life adversities [1]. Not all individuals develop psychological maladjustments under stressful life situations, e.g., [2]. Such attributes may be a flexible adapting capacity rather than a rigid resisting quality to stressful situations. Many researchers have described this concept as resilience [3, 4]. Masten, Best, and Garmezy [5] have defined resilience as "the process of, capacity for, or outcome of successful adaptation despite challenging or threatening circumstances".

Richardson [6] has reviewed the literature on resilience and noted that there are three distinct periods of research. In the first period, researchers were interested in phenomenological descriptions of the resilient qualities of individuals and support systems, which predict social and personal success. Here the concept of resilience was used in the field of positive psychology. In the second period, researchers recognized that resilience was not merely a trait, but the process of coping with stressors, adversities, change, or opportunity in a manner, which resulted in the identification, fortification, and enrichment of protective factors. In the third period, resilience was viewed as a multidisciplinary identification of motivational forces within individuals and groups, and the creation of experiences, which fostered the activation and utilization of the forces.

*Address correspondence to this author at the Kumamoto University Graduate School of Medical Sciences, Japan;

E-mail: kitamura@kumamoto-u.ac.jp

${ }^{\S}$ All the authors equally contributed to the manuscript.
The various definitions and uses of the term have made it necessary to create an operational direct measure of resilience, e.g., [7]. Following a literature review, Wagnild and Young $[8,9]$ conceptualized resilience as a positive personality characteristic, which would enhance individual adaptations, including equanimity (a balanced perspective of one's life and experiences), perseverance (an act of persistence despite adversity or discouragement), self-reliance (a belief in oneself and one's capabilities), meaningfulness (the realization that life has a purpose and the valuation of one's contribution), and existential aloneness (the realization that each person's life path is unique). Based on this conceptualization, they established the Resilience Scale (RS) and validated it [10-12].

The RS was translated into Japanese. It is of clinical and research interest to examine whether a measure such as the $\mathrm{RS}$, which was developed in a Western culture, is reliable and valid in a non-Western culture. This is the first report on the validity of the RS in a Japanese university student population. The aims of this report are to examine (1) the internal consistency and factor structure of the RS, (2) the construct validity of the RS by investigating the relationships between the RS and several measures of psychosocial variables, (3) the extent to which social desirability influences the response of the participants, and (4) the RS's potency to predict subsequent depression.

A new measure's construct validity should be examined by its relationships with a variety of measures, which are recognized to be theoretically related to the measure scores. The first variable used as a construct validity measure in this study is depression and suicidality. Because resilience functions as a buffer to the impact of stressful life situations by protecting individuals from feeling despondent or suicidal, we hypothesized that the RS score would be negatively correlated with depressive mood [10, 13-15] and suicidal thought. 
The RS score may also be correlated with adaptive coping styles [16]. Coping is an important resource for the psychological adaptation to stressful situations [17-19]. Lazarus and Folkman [20] have proposed two coping strategies: problem-focused and emotion-focused, while Endler and Parker [21] have proposed three categories after a factorial analysis of different coping behaviors: task-, emotion-, and avoidance-oriented coping. Many reports have shown that a task-oriented coping style is linked to adaptive health variables [21-24]. On the other hand, an emotion-oriented coping style has been reported to be associated with negative health variables such as depression, anxiety, and poor recovery from bodily illnesses $[19,21,25,26]$. The effects of the avoidance-oriented coping style on the health variables have been controversial [21, 27-31]. Thus, we expected that the RS scores would be positively linked to a task-oriented coping style, but negatively linked to an emotion-oriented coping style. We were unable to anticipate the measure's link to an avoidance-oriented coping style.

Furthermore, resilience may be linked to better interpersonal relationships [32]. Bowlby [33, 34] has argued that a child's imprinted style of attachment to the mother will remain throughout life, and will work as a 'standard' relating mode of adolescents and adults with their significant others, including romantic partners and spouses. Hence, attachment styles among adults are an important aspect of the relationship with one's significant other. Similar to babies, adult attachment may be secure or insecure [35]. In the domain of intimate relationship, we hypothesized that the RS score would be correlated with secure adult attachment.

Resilience reflects healthy ego function. People with healthy ego function are expected to adaptively control selffocused emotions because self-focused emotions are based on interpersonal interactions, evaluations, and judgments of each other [36]. Tangney and her colleagues classified selffocused emotions into (1) shame, (2) guilt, (3) externalization, (4) detachment, (5) alpha pride, and (6) beta pride [3739]. They have reported that negative affects such as depression and anger are associated with shame, but not with guilt. Thus, we expected that the RS score would be negatively correlated with a shame feeling, but not with a guilt feeling. People high in resilience may feel more pride than those low in resilience. Hence, resilience may be correlated with healthy narcissism such as feeling assertive and superior to others. People low in resilience may also be more likely to have personality disorder pathology. In this study, we were particularly interested in borderline personality. The RS scores may be correlated with a maladaptive defense mechanism seen among people with such personality structures.

Finally, if resilience is a product of an optimal rearing environment, we expect it to be related to the psychosocial environment where individuals have grown. There has been an anecdotal report that memories of parents are important for the development of resilience [2]. An area of early life experiences studied in relation to mental health is the perceived rearing by parents. There have been several studies suggesting that optimal rearing as a child is associated with psychological adaptation as an adult [40-43]. Another important area is the experience of child abuse. It is known that various types of child abuse experiences influence subsequent personality development, and often underlie the occur- rence of mental disorders [44-46]. Hence, we anticipate that people high in resilience would report their parents as more affectionate and respecting children's autonomy, and people low in resilience may have been victims of child abuse.

\section{METHOD}

\section{Participants}

As a part of a longitudinal follow-up study on the depressive mood and suicidality among a Japanese university student population, a 9-wave prospective study was performed using students from two universities in Kumamoto, Japan. The number of eligible students was 848 , but not all the students attended each occasion and some $(2 \%$ to $3 \%$ of the attending students) refrained from participating in the study. Thus, usable data were obtained from 504 to 547 students on each occasion (Table 1).

The RS was included in the questionnaire on the fourth occasion. On this occasion, there were 525 participants, but seven students were older than 25 , and were excluded from the subsequent analyses because we aimed to obtain a group of students with a homogenous age. These 518 students included 117 men and 401 women. Their mean (SD) age was 19.0 (1.0) years.

\section{Measurements}

Resilience Scale (RS): The RS [9] is a self-report measure, which consists of 25 items on a 5-point scale from "disagree $=1 "$ to "agree $=5 "$ ". Wagnild and Young [9] have proposed two subcategories, personal competence and acceptance of self and life, based on a principal component analysis. Although the original RS was rated on a 7-point scale (0 = disagree, $6=$ agree), we modified the number of choices to five in order to adjust the number of the choices to match most of the other questionnaires in this study. The original English version [9] was translated into Japanese by $\mathrm{CH}$ with permission from the original author (Dr. Wagnild). The Japanese version was retranslated back into English by a person who was blind to the original English version. This was verified by the original author in order to confirm its face validity.

Zung Self-rating Depression Scale (ZSDS): The ZSDS [47] is a self-report measure of depressive symptoms, which consists of items on a 4 -point scale $(0=$ never, $3=$ almost always). Using a Japanese university student population, Kitamura, Hirano, Chen, \& Hirata [48] have reported a three-factor structure for the scale. They include affective, cognitive, and somatic symptoms. In the present study, we used only seven ZSDS items, which were categorized as affective in that factor analysis. Mean values were substituted for a missing item only when 5 out of 6 items were answered.

Stressful Life Events Scale (SLES): The life event that had occurred in the last week was measured by an ad hoc single item, "Consider things happening in the last week that were undesirable, upsetting, unhappy, awful, or saddening, and estimate the impact that they had on you. Rate it as 0 if there were not negative effects and 100 if they were the worst". In many studies, life events are measured by counting the number of specified life events that are usually weighted according to either predetermined coefficients or 
situation specific contextual threat. However, subjective distress has been reported to be correlated to psychological symptoms more strongly than the number of event happening or the weighted objective impacts of the events $[49,50]$. A single item perceived stress scale has been used in several studies (e.g., [51]).

Table 1. Number of Participants, Gender Ratio, Mean (SD) Age on Each Test Occasion

\begin{tabular}{|c|c|c|c|}
\hline Test Occasions & $\mathbf{n}$ & Men (\%) & Age \\
\hline \hline Wave 1 & 546 & 22.7 & $19.0(1.5)$ \\
\hline Wave 2 & 545 & 22.8 & $19.0(1.5)$ \\
\hline Wave 3 & 547 & 23.4 & $19.1(1.5)$ \\
\hline Wave 4 & 525 & 22.9 & $19.1(1.5)$ \\
\hline Wave 5 & 521 & 22.6 & $19.1(1.5)$ \\
\hline Wave 6 & 512 & 23.8 & $19.0(1.3)$ \\
\hline Wave 7 & 504 & 24.0 & $19.0(1.4)$ \\
\hline Wave 8 & 509 & 22.2 & $19.1(1.3)$ \\
\hline Wave 9 & 531 & 23.0 & $19.0(1.3)$ \\
\hline
\end{tabular}

SD in brackets.

Suicidality: To assess the current suicidal idea of the students, we used a single item reflecting suicidality in the ZSDS. This was rated on a 4 -point scale $(0=$ never, $3=$ almost always).

Coping Inventory for Stressful Situations (CISS): The CISS [21] is a self-report measure of coping patterns. It consists of 48 items on a 5 -point scale $(0=$ not at all, $4=$ very much). There are three subcategories: Task-oriented Coping, Emotion-oriented Coping, and Avoidance-oriented Coping. Task-oriented Coping is adaptive and outlines priorities, determines a course of action, and follows through with the action involved. Emotion-oriented Coping involves blaming oneself about the situation or events and becoming preoccupied with worrying about them. Avoidance-oriented Coping involves participation in other activities as a way of ignoring the problem. Higher scores indicate a greater use of a given coping style. Furukawa, Suzuki, Saito, and Hamanaka [52] have provided a Japanese translation of the measure and have demonstrated its reliability and validity. Mean values were substituted for missing items when at least 39 out of the 48 items were answered.

Relationship Questionnaire (RQ): The RQ [35] is a selfreport measure of adult attachment style. It consists of four sentences, which describe a specific attachment style. They include Secure, Fearful, Preoccupied, and Dismissing. Each participant was asked to rate the extent to which each description corresponds to his or her relationship with his or her partner. If he or she did not have a definite partner, then he or she was requested to imagine a close opposite-sex person when answering the question. Its reliability [35] and validity [53] have been reported. Each sentence was rated on a 7 -point scale $(0=$ Does not apply to me at all, $6=$ Applies to me very much). With Dr. Bartholomew's permission, the RQ was translated into Japanese (T.K.). Because a single-factor structure has been demonstrated for the RQ among a Japa- nese university student population (Matsuoka, Uji, Hiramura, Chen, Shikai, Kishida, \& Kitamura, 2006), we calculated the RQ total score as the score of Secure subtracted by the scores of the remaining three insecure attachment styles. Thus, the possible range was -18 to 6 .

Test of Self-Conscious Affect-3 (TOSCA-3). This is a selfreport measure of six self-conscious affects: shame, guilt, externalization, detachment, alpha pride, and beta pride [55]. The TOSCA-3 consists of a series of eleven negative and five positive scenarios with four or five responses reflecting one of the six affects. Each response is rated on a 5-point scale $(0=$ not likely, $4=$ very likely $)$. A bilingual student translated the TOSCA-3 into Japanese, while a second bilingual graduate student familiar with the literature on shame and guilt back-translated the measure and compared it with the original English. The validation of the Japanese version of the measure has been reported (Hasui C, Kitamura T, Tamaki A, Takahashi M, Masuda S, Ozeki N. The Test of Self-Conscious Affect-3 in Japanese University Students. submitted). Mean values were substituted for missing items when at least 56 out of 69 items were answered.

Narcissistic Personality Inventory (NPI): The NPI [56] is a self-report measure initially with 233 items, which were divided into two forms. Emmons [57] has revised it into a 54-item measure. For the Japanese adaptation, Oshi [58] has developed an 18-item measure on a 5-point scale (NPI-S). We allocated between 0 to 4 points for each item. The NPI-S consists of three subcategories: Feeling Superior (6 items), Desire for Admiration (6 items), and Assertiveness (6 items). Oshio (2004) has suggested that the NPI-S reflects a healthy, adaptive aspect of the ego function. Mean values were substituted for missing items when at least 15 out of the 18 items were answered.

Inventory of Personality Organization (IPO): The IPO [59] is a self-report measure, which consists of 83 items on a 5 -point scale $(0=$ never true, $4=$ always true $)$. This tool was developed based on the central dimension of Kernberg's [60] personality organization model: primitive psychological defenses, identity diffusion, and reality testing. These dimensions are measured by the three primary scales of the IPO: Primitive Defenses (16 items), Identity Diffusion (21 items), and Reality Testing (20 items). In addition, two more scales, Aggression (18 items) and Moral Values (8 items with 2 Primitive Defenses items and 1 Identity Diffusion item) were added. Lenzenweger, Clarkin, Kernberg, and Foelsch [61] and Critchfield, Levy, and Clarkin [62] have reported the psychometric properties of the original IPO. With the original author's permission, we translated this inventory into Japanese. To verify the accuracy of the translation, the Japanese version was back-translated into English by a translator unfamiliar with the original document. Mean values were substituted for missing items when at least 67 out of the 83 items were answered.

Parental Bonding Instrument (PBI): The PBI [63] is a self-report questionnaire to retrospectively assess a parental attitude toward the subject as a child. The 25 items were scored on a 4-point scale ( 0 = very unlikely, $3=$ very likely $)$. There are two subcategories: Care (12 items) and Overprotection (13 items). Higher scores reflect a higher Care or higher Overprotection experience. A good reliability has been reported for the PBI [63]. Kitamura and Suzuki [64, 65] 
have translated the PBI with a back-translation into English to verify the wording. The validity of the instrument has been confirmed by the high agreement between the PBI scores of each parent recorded independently by the student, and his or her father and mother. Mean values were substituted for missing items when at least 20 out of the 25 items were answered.

Child Abuse and Trauma Scale (CATS): The CATS [66] is a self-report measure of the experiences of sexual abuse, neglect, and punishment (physical abuse). It consists of 38 items on a 5-point scale ( $0=$ never, $4=$ always $)$. It has three subcategories: Sexual Abuse (6 items), Neglect (14 items), and Punishment ( 6 items). Mean values were substituted for missing items when at least 31 out of the 38 items were answered.

Social Desirability Scale (SDS): The SDS [67] is a selfreport measure of the participant's response style. The SDS has been translated into Japanese (TK) and 10 items are found to be suitable for a Japanese population [68]. Each item is answered on a 5 -point scale $(0=$ not true, $3=$ true $)$. Mean values were substituted for missing items when at least 8 out of the 10 items were answered.

\section{Procedure}

A set of questionnaires were distributed and returned by a lecturer of the class. It was announced orally before distributing the questionnaire and written on the face sheet that students had a right to refrain from participating, and it would never result in any academic disadvantages. Anonymity was confirmed, but due to necessity of matching questionnaires from different occasions for each student, students were requested to create a unique "nickname" and use it whenever they answered a questionnaire.

Different measures were included in the questionnaires on different occasions. Thus, the RS and ZSDS were included in the questionnaire on the $4^{\text {th }}$ occasion; the CISS on the first occasion; the RQ, NPI, and SDS on the $5^{\text {th }}$ occasion; the TOSCA on the $6^{\text {th }}$ occasion; the IPO on the $7^{\text {th }}$ occasion; the PBI on the third occasion; and the CATS on the $2^{\text {nd }}$ occasion. The SDS and SLES were also used on $6^{\text {th }}$ occasion (two weeks later after the application of the RS) as the dependent variables for the predictive validity study of the RS. The number of the participants available for each analysis is noted in a bracket.

This study project was approved by the Ethical Committee of the Kumamoto University Graduate School of Medical Sciences (equivalent to the Institutional Review Board).

\section{Statistical Analyses}

After calculating the internal consistency of the RS using Cronbach's alpha coefficient, the RS items were entered into a factor analysis. Single- and two-factor models were com- pared in terms of chi-squared, goodness-of-fit index (GFI), adjusted goodness-of-fit index (AGFI), comparative fit index (CFI), and root mean square error of approximation (RMSEA). The Akaike Information Criteria (AIC) was applied to judge which model fit the data better [69]. The RS score was correlated with the rating scales used as the construct validity measures. Due to multiple comparisons, we set $p$ at .001 . Finally, the predictive validity of the RS was examined using a regression analysis in which the SDS scores two weeks later were regressed on three steps. First, the age and sex were forced into the regression formula. Second, the baseline (the fourth occasion) SDS was entered. Third, the NLES scores two weeks later (the sixth occasion) were entered. Fourth, the RS scores were entered. Finally, the interactions of these variables were examined by entering the composite variables, including the NLES (two weeks later) divided by the RS as well as the baseline SDS divided by the RS.

All statistical analyses were conducted using the Statistical Package for Social Science (SPSS) version 13.0 and Amos 5.0.

\section{RESULTS}

\section{Factor Structure}

The eigenvalues of the first five factors were 8.7, 1.5, 1.4, 1.1, and 1.0, respectively, suggesting a single factor structure. The Cronbach's alpha coefficient was .60, and did not increase substantially if one item each was omitted from the analysis. The highest alpha was .63 when item 21 was omitted from the analysis.

We compared the single-factor structure model with the two-factor structure model proposed by Wagnild and Young (1993) using confirmatory factor analysis (Table 2). The goodness-of-fit indices of the two models were virtually identical. Moreover, the two factors according to Wagnild and Young (1993) model shared the greatest covariance of .99.

\section{Construct Validity}

As expected, the RS scale scores were negatively correlated with both SDS depressive symptoms and suicidality scores (Table 3). Students with high RS scores were more likely to adopt a Task-oriented Coping Style and less likely to adopt an Emotion-oriented Coping Style. In addition, their adult attachment was more likely to be secure. They were also less prone to the Shame feeling, but more prone to Alpha and Beta Prides. Furthermore, their scores were also positively correlated with two of the NPI-S subcategories and negatively correlated with the IPO Identity Diffusion and Aggression scores. Moreover, they were more likely to perceive their parents more affectionate, their mother less overprotective, and reported less frequent experiences of Punishment as a child.

Table 2. Confirmatory Factor Analyses of the Resilience Scale

\begin{tabular}{|c|c|c|c|c|c|c|c|c|}
\hline Model of the Factor Structure & $\mathrm{Chi}^{2}$ & $d f$ & $\mathrm{Chi}^{2} / d f$ & GFI & AGFI & CFI & RMSEA & $\mathbf{A I C}$ \\
\hline Single-factor model & 1218.9 & 276 & 4.4 & .834 & .804 & .800 & .081 & 1316.9 \\
\hline Two-factor model with covariance between the two factors & 1217.4 & 275 & 4.4 & .834 & .804 & .800 & .081 & 1317.4 \\
\hline
\end{tabular}


Table 3. Correlates of the RS Scores

\begin{tabular}{|c|c|c|c|c|}
\hline & Possible Range & Mean (SD) & Cronbach's Alpha & Correlation with the RS \\
\hline Resilience Scale (RS) & $0-150$ & $47.4(16.2)$ & & - \\
\hline \multicolumn{5}{|l|}{ SDS } \\
\hline Depressive symptoms & $0-18$ & $4.6(4.2)$ & .869 & $-.33 * * *(N=514)$ \\
\hline Suicidality & $0-3$ & $0.25(0.68)$ & NA & $-.29 * * *(\mathrm{~N}=514)$ \\
\hline \multicolumn{5}{|l|}{ CISS } \\
\hline Task-oriented coping & $0-64$ & $27.7(11.6)$ & .897 & $.50 * * *(N=443)$ \\
\hline Emotion-oriented coping & $0-64$ & $21.7(11.1)$ & .847 & $-.29 * * *(N=443)$ \\
\hline Avoidance-oriented coping & $0-64$ & $27.4(10.2)$ & .810 & $.15 * *(\mathrm{~N}=443)$ \\
\hline \multicolumn{5}{|l|}{$R Q$} \\
\hline Adult attachment & $-18-6$ & $-3.2(4.4)$ & .361 & $.33 * * *(N=452)$ \\
\hline \multicolumn{5}{|l|}{ TOSCA } \\
\hline Shame & $0-64$ & $35.8(9.0)$ & .784 & $-.26 * * *(N=439)$ \\
\hline Guilt & $0-64$ & $47.5(8.4)$ & .819 & $.05(\mathrm{~N}=439)$ \\
\hline Externalization & $0-64$ & $19.4(8.1)$ & .739 & $-.05(\mathrm{~N}=439)$ \\
\hline Detachment & $0-44$ & $18.2(6.6)$ & .716 & $.13 * *(\mathrm{~N}=439)$ \\
\hline Alpha pride & $0-20$ & $10.7(3.4)$ & .590 & $.26 * * *(N=439)$ \\
\hline Beta pride & $0-20$ & $11.3(3.4)$ & .553 & $.19 * * *(N=439)$ \\
\hline \multicolumn{5}{|l|}{$N P I-S$} \\
\hline Feeling superior & $0-24$ & $4.9(4.1)$ & .891 & $.55 * * *(N=397)$ \\
\hline Desire for admiration & $0-24$ & $9.7(4.4)$ & .812 & $.15 * *(\mathrm{~N}=397)$ \\
\hline Assertiveness & $0-24$ & $9.4(4.4)$ & .774 & $.61 * * *(N=397)$ \\
\hline \multicolumn{5}{|l|}{ IPO } \\
\hline Primitive defences & $0-64$ & $17.9(9.7)$ & .856 & $-.13 *(\mathrm{~N}=423)$ \\
\hline Identity diffusion & $0-84$ & $29.3(14.6)$ & .901 & $-.19 * * *(\mathrm{~N}=423)$ \\
\hline Reality testing & $0-80$ & $14.3(11.5)$ & .900 & $-.14 * *(\mathrm{~N}=423)$ \\
\hline Aggression & $0-72$ & $7.3(8.7)$ & .899 & $-.23 * * *(N=423)$ \\
\hline Moral values (superego) & $0-44$ & $7.8(6.3)$ & .808 & $-.16 * *(\mathrm{~N}=423)$ \\
\hline \multicolumn{5}{|l|}{$P B I$} \\
\hline Father's care & $0-36$ & $25.8(7.4)$ & .891 & $.26 * * *(N=460)$ \\
\hline Father's overprotection & $0-39$ & $10.1(5.9)$ & .792 & $-.15 * *(\mathrm{~N}=458)$ \\
\hline Mother's care & $0-36$ & $29.6(5.7)$ & .858 & $.27 * * *(N=361)$ \\
\hline Mother's overprotection & $0-39$ & $10.6(6.4)$ & .825 & $-.26 * * *(N=354)$ \\
\hline \multicolumn{5}{|l|}{ CATS } \\
\hline Sexual abuse & $0-24$ & $.03(1.3)$ & .715 & $.00(\mathrm{~N}=449)$ \\
\hline Neglect & $0-56$ & $10.1(8.1)$ & .836 & $-.12 *(\mathrm{~N}=449)$ \\
\hline Punishment & $0-24$ & $7.5(3.7)$ & .528 & $-.17 * * *(N=449)$ \\
\hline \multicolumn{5}{|l|}{$S D S$} \\
\hline Social Desirability Scale & $0-30$ & $19.4(4.4)$ & .543 & $.21 * * *(N=389)$ \\
\hline \multicolumn{5}{|l|}{ Demographics } \\
\hline Gender (men 1; women 2) & $1-2$ & $1.8(0.4)$ & NA & $-.06(\mathrm{~N}=517)$ \\
\hline Age & $18-25$ & $19.0(1.0)$ & NA & $.07(\mathrm{~N}=517)$ \\
\hline
\end{tabular}

${ }^{*} P<.05 ;{ }^{* *} P<.01 ; * * * P<.001 ; \mathrm{NA}$, not applicable; statistically significant coefficients are in bold. 
Table 4. Regression of the Subsequent ZSDS Scores on the Predictor Variables

\begin{tabular}{|c|c|c|c|}
\hline & $\mathbf{R}^{2}$ Increase & F Increase & Standardised Beta \\
\hline Step 1: demographic variables & .024 & $4.1(2,428) * *$ & \\
\hline Sex & & & .012 \\
\hline Step 2: baseline depression & .521 & $451.5(1,427) * * *$ & \\
\hline Step 3: negative life events & .056 & $55.8(1,426) * * *$ & \\
\hline NLES 2 weeks later & & & $.249 * * *$ \\
\hline Step 4: resilience & .008 & $6.9(1,425) * *$ & \\
\hline RS & & & $-.090 * *$ \\
\hline Adjusted $\mathrm{R}^{2}$ total & .603 & & \\
\hline
\end{tabular}

\section{Prediction of Subsequent Depression: Main Effect and Interaction}

Regression analysis was performed to examine the impact of resilience on the subsequent severity of depression. The baseline SDS followed by NLES and RS scores provided the most robust contribution of the variables in predicting the SDS scores two weeks later (Table 4). Thus, after controlling the effects of the baseline depression severity and the negative life events, the resilience remained a potent predictor of subsequent depression. However, the interaction of the RS with either the NLES or baseline SDS scores failed to show a significant prediction.

\section{DISCUSSION}

The present study has demonstrated a good internal consistency of the RS. We have also compared the two-factor and one-factor models of the RS items. Aroian et al. [10] have studied Soviet immigrants using the Russian version of the RS, and noted that their two-factor model fit the data better than the one-factor model. Nevertheless, their two factors were strongly correlated $(r=.67)$ and they compared the two models only in terms of chi-squared/df, GFI, and AGFI, but did not apply the AIC. Because neither of the two models in this study presented a definite superiority, and the two factors of the Wagnild and Young [9] model shared a covariance of almost unity, and all the RS items reflected people's psychological adjusting capacity, we think that the single factor model should be used in subsequent practice and research. Even in the one-factor model, however, the goodness-of-fit indices were not very impressive and were mediocre. Further refinement of the structure of the RS would be required in future studies of the RS in its Japanese and possibly English versions. Some items may have to be either deleted or exchanged with new items. Nevertheless, we used the original items in this study because we were interested in the comparison with the English original version.
The reliability of psychological measures should be assessed not only by internal consistency as proved in the present study but also by test-retest reliability. The latter should be demonstrated for a measure to be regarded as a stable psychological trait. The Japanese version of the RS should be examined for its test-retest reliability in the future.

As for the construct validity of the RS, we have observed that the RS is associated with external validation variables towards the expected direction. Similar to numerous previous studies [10,13-15], people who were low in resilience are more likely to show depressive symptoms. In addition, they are more likely to have suicidal ideation. Because the number of suicidal deaths in Japan has sharply increased since 1998, the link between resilience and suicidality should be further examined in order to establish effective preventive measures of suicidal attempts and death.

As expected, this study demonstrates that resilient students use adaptive coping strategies and have secure relationships with intimate partners. These psychological resources are very important for students to maintain their capacity to cope with life difficulties and adversities. Shikai, Uji, Chen, et al. [70] have found that self-efficacy predicts an adaptive coping style. The former is an important compartment of resiliency. The complicated link between these concepts warrants further investigation. Student who are high in resiliency have the potential to maintain stable interpersonal relationships, particularly with an intimate person. As expected, these students show secure intimate relationships with romantic partners.

Furthermore, the findings agreed with our hypothesis that resiliency is linked to intrapsychic characteristics such as a lower shame feeling, higher pride feelings, higher healthy narcissistic traits, and lower borderline personality traits. The present findings are consistent with the literature in which the lack of these traits is listed as risk factors of psychopathology. 
The present study has examined the correlates of resilience in personal history variables. As expected, those students who were low in resiliency reported their parents as less caring, more overprotective, and more physically abusive. Among the PBI scores, only the father's Overprotection score failed to show a significant association with the RS score. The studies on the association between adult depression and perceived rearing as a child generally indicate that people who experienced depression as an adult are more likely to report low paternal or maternal care and overprotection $[41,71-80]$. Yet, these findings are not always consistent. Even in the present study, the father's Overprotection was negatively, though not significantly, correlated with a lower RS score.

The predictive validity of the RS is confirmed by the finding that the RS scores predicted depressive mood two weeks later even after controlling the concurrent depressive mood and the stressful life events, which occurred in the previous week. However, contrary to our expectation, the RS and depressive mood or stressful life events did not interact with each other in terms of predicting subsequent depression. This study may have examined only mild to moderate stressful life events, and resilience may function as a moderator only when the stressor is of a substantive magnitude. People high in resilience may feel as depressed as those low in resilience when encountering life adversities, but those with high resilience may be more likely to recover in a shorter time span. This requires further studies, which include clinical cases.

A drawback of the RS may be its moderate, but significant association with social desirability. Obviously RS items seem to be traits that many people would recognize as socially desirable. Thus, the data, including the RS, should be cautiously interpreted.

Limitations of this study should be commented. A lack of proof of the test-retest reliability of the RS has already been noted. Another limitation is the use of a non-random young student population. Caution should be exercised before the present findings are extrapolated into other populations such as middle-aged or older populations or clinical populations.

\section{CONCLUSIONS}

The Japanese version of the RS has been shown to be an internally consistent and valid measure of resilience. Employing the RS in research and clinical settings in Japan may open avenues for further understanding the psychological resources of non-clinical and clinical populations in Japan.

\section{REFERENCES}

[1] Patterson JM. Understanding family resilience. J Clin Psychol 2002; 58: 233-46.

[2] Rak CE, Patterson LE. Promoting resilience in at-risk children. J Couns Dev 1996; 74: 368-73.

[3] Beardslee WR. The role of self-understanding in resilient individuals: The development of a perspective. Am J Orthopsychiatry 1989; 59: 266-78.

[4] Rutter M. Resilience in the face of adversity: Protective factors and resilience to psychiatric disorder. Br J Psychiatry 1985; 147: 598611

[5] Masten AS, Best KM, Garmzy N. Resilience and development: Contributions from the study of children who maltreatment on social competence and behavior problems. Dev Psychopathol 1990; 6: 121-43.
[6] Richardson GE. The metatheory of resilience and resiliency. J Clin Psychol 2002; 58: 307-21.

[7] Klohnen EC. Conceptual analysis and measurement of the construct of ego-resilience. J Pers Soc Psychol 1996; 70: 1067-79.

[8] Wagnild GM, Young HM. Resilience among older women. IMAGE: J Nurs Sch 1990; 22: 252-5.

[9] Wagnild GM, Young HM. Development and psychometric evaluation of the resilience scale. J Nurs Meas 1993; 1: 165-78.

[10] Aroian KJ, Shappler-Morris N, Neary S, Spitzer A, Tran TV. Psychometric evaluation of the Russian language version of the resilience scale. J Nurs Meas 1997; 5: 151-64.

[11] Christopher K. Determinants of psychological well-being in Irish immigrants. West J Nurs Res 2000; 22: 123-43.

[12] Wagnild GM. Resilience and successful aging: Comparison among low and high income older adults. J Gerontol Nurs 2003; 29: 42-9.

[13] Aroian KJ, Norris AE. Resilience, stress, and depression among Russian immigrants to Israel. West J Nurs Res 2000; 22: 54-67.

[14] Heilemann MV, Lee KA, Kury FS. Strengths and vulnerablities of women of Mexican descent in relation to depressive symptoms. Nurs Res 2002; 51: 175-82.

[15] Miller AM, Chandler PJ. Acculturation, resilience, and depression in midlife women from the former Soviet Union. Nurs Res 2002; 51: 26-40.

[16] Felten BS, Hall JM. Conceptualizing resilience in women older than 85. J Gerontol Nurs 2001; 27: 46-53.

[17] Cooper C, Katona C, Orrell M, Livingston G. Coping strategies and anxiety in caregivers of people with Alzheimer's disease: The LASER-AD study. J Affect Disord 2006; 90: 15-20.

[18] Enns MW, Cox BJ. Psychosocial and clinical predictors of symptom persistence $v s$ remission in major depressive disorder. Canad $\mathrm{J}$ Psychiatry 2005; 50: 769-77.

[19] Vollrath M, Alnaes R, Torgersen S. Coping and MCMI-2 symptom scales. J Clin Psychol 1994; 50: 727-36.

[20] Lazarus RS, Folkman S. Stress, Appraisal, and Coping. New York: Springer 1984.

[21] Endler NS, Parker JDA. Coping Inventory for Stressful Situations (CISS): Manual. Toronto: Multi-Health Systems, Ins. 1990.

[22] Miller SM, Brody DS, Summerton S. Styles of coping with threat: Implications for health. J Pers Soc Psychol 1988; 54: 142-8.

[23] Parkes KR. Coping, negative affectivity, and the work environment: Additive and interactive predictors of mental health. J Appl Psychol 1990; 75: 399-409.

[24] Endler NS, Parker JDA, Butcher JN. A factor analytic study of coping styles and the MMPI-2 content scales. J Clin Psychol 1993; 49: 523-7.

[25] Billings AG, Cronkite RC, Moos RH. Social-environmental factors in unipolar depression: Comparisons of depressed patients and nondepressed controls. J Abnorm Psychol 1983; 92: 119-33.

[26] McWilliams LA, Cox BJ, Enns MW. Use of the Coping Inventory for Stressful Situations in a clinically depressed sample: factor structure, personality correlates, and prediction of distress. J Clin Psychol 2003; 59: 423-37.

[27] Holahan CJ, Moos RH. Personal and contextual determinants of coping strategies. J Pers Soc Psychol 1987; 52: 946-55.

[28] Krantz SE, Moos, RH. Risk factors at intake predict nonremission among depressed patients. J Consult Clin Psychol 1988; 56: 863-9.

[29] McCrae RR, Costa PT Jr. Personality, coping and coping effectiveness in an adult sample. J Pers 1986; 54: 385-405.

[30] Cronkite R, Moos R, Twohey J, Cohen C, Swindle R. Life circumstances and personal resources as predictors of the ten-year course of depression. Am J Comm Psychol 1998; 26: 255-80.

[31] Park CL, Adler NE. Coping style as a predictor of health and wellbeing across the first year of medical school. Health Psychol 2003; 22: 627-31.

[32] Monteith B, Ford-Gilboe M. The relationships among mother's resilience, family health work, and mother's health promoting lifestyle practice in families with preschool children. J Fam Nurs 2002; 8: 383-407.

[33] Bowlby J. Attachment and Loss: Separation: Anxiety and Anger. New York: Basic Books; 1973; Vol. 2.

[34] Bowlby J. Developmental psychiatry comes of age. Am J Psychiatry $1988 ; 145: 1-10$.

[35] Bartholomew K, Horowitz LM. Attachment styles among young adults: A test of four-category model. J Pers Soc Psychol 1991; 61: 226-44. 
[36] Fisher KW, Tangney JP. Self-conscious emotions and the affect revolution: Framework and overview. In: Tangney JP, Fisher KW, Eds. Self-conscious emotions: the psychology of shame, guilt, embarrassment, and pride. New York: Guilford Press 1995:3-22.

[37] Tangney JP. Assessing individual differences in proneness to shame and guilt: Development of the self-conscious affect and attribution inventory. J Pers Soc Psychol 1990; 59: 102-11.

[38] Tangney JP. Moral affect: The good, the bad, and the ugly. J Pers Soc Psychol 1991; 61: 598-607.

[39] Tangney JP, Wagner P, Fletcher C, Gramzow R. Shamed into anger? The relation of shame and guilt to anger and self-reported aggression. J Pers Soc Psychol 1992; 62: 669-75.

[40] Levy KN, Blatt SJ, Shaver PR. Attachment styles and parental representations. J Pers Soc Psychol 1998; 74: 407-19.

[41] Parker G. Parental Overprotection: A Risk Factor in Ppsychological Development. New York: Grune \& Stratton 1983.

[42] Roseman S, Rogers B. Childhood adversity and adult personality. Aust NZ J Psychiatry 2006; 40: 482-90.

[43] Sato T, Uehara T, Narita T, Sakado K, Fujii Y. Parental bonding and personality in relation to a life history of depression. Psychiatry Clin Neurosci 2000; 54: 121-30.

[44] Coid J, Petruckevitch A, Chung W-S, Richardson J, Moorey S, Feder G. Abusive experiences and psychiatric morbidity in women primary care attenders. Br J Psychiatry 2003; 183: 332-9.

[45] Danese A, Pariante CM, Caspi A, Taylor A, Poulton R. Childhood maltreatment predicts adult inflammation in a life-course study. Proc Natl Acad Sci USA 2007; 104: 1319-24.

[46] Elliot GC, Cunningham SM, Linder M, Colangelo M, Gross M. Child physical abuse and self-perceived social isolation among adolescents. J Interpers Violence 2005; 20: 1663-384.

[47] Zung WWK. A self-rating depression scale. Arch Gen Psychiatry 1965; 12: 63-70.

[48] Kitamura T, Hirano H, Chen Z, Hirata M. Factor structure of the Zung Self-rating Depression Scale in first-year university students in Japan. Psychiatry Res 2004; 128: 281-7.

[49] Cohen S, Kamarck T, Mermelstein R. A global measure of perceived stress. J Health Soc Behav 1983; 24: 385-96.

[50] Tennant $\mathrm{C}$, Andrews G. The pathogenic quality of life event stress in neurotic impairment. Arch Gen Psychiatry 1978; 35: 859-63.

[51] Austin M-P, Hadzi-Pavlovic D, Leader L, Saint K, Parker G. Maternal trait anxiety, depression and life event stress in pregnancy: Relationships with infant temperament. Early Hum Dev 2005; 81: 181-90.

[52] Furukawa T, Suzuki A, Saito Y, Hamanaka T. Reliability and validity of the Japanese version of the Coping Inventory for Stressful Situations (CISS): A contribution to the cross-cultural studies of coping. Psychiat Neurol Jpn 1993; 95: 602-21.

[53] Griffin DW, Bartholomew K. The metaphysics of measurement: The case of adult attachment. In: Bartholomew K, Perlman D, eds. Advances in personality relationship Attachmentprocesses in Adulthhood. Jessica Kingsley Publishers: London 1994; vol. 5: pp. 7-52

[54] Matsuoka N, Uji M, Hiramura H, Chen Z, Shikai N, Kishida Y, Kitamura T. Adolescents' attachment style and early experiences: A gender difference. Arch Women Ment Health 2006; 9: 23-9.

[55] Tangney JP, Dearing R, Wagner PE, Gramzow R. The Test of SelfConscious Affect -3 (TOSCA-3). Fairfax: George George Mason University, 2000.

[56] Raskin R, Hall CS. A narcissistic personality inventory. Psychol Rep 1979; 45: 590.

[57] Emmons RA. Factor analysis and construct validity of the Narcissistic Personality Inventory. J Pers Assess 1984; 48: 291-300.

[58] Oshio A. Jikoai no seinen shinrigaku The adolescent Psychology of Narcissism. Tokyo: Nakanishiya, 2004

[59] Clarkin J, Foelsch PA, Kernberg OF. The Inventory of Personality Organization (IPO). Personality Disorder Institute, Department of
Psychiatry, New York, NY: Weill College of Medicine of Cornell University 2001

[60] Kernberg OF. Borderline Conditions and Pathological Narcissism. New York: Jason Aronson 1975.

[61] Lenzenweger MF, Clarkin JF, Kernberg OF, Foelsch PA. The inventory of personality organization: psychometric properties, factor composition, and criterion relations with affect aggressive dyscontrol, psychosis proneness, and self-domains in a nonclinical sample. Psychol Assess 2001; 13: 577-91.

[62] Critchfield KL, Levy KN, Clarkin JF. The relationship between impulsivity, aggression, and impulsive-aggression in borderline personality disorder: an empirical analysis of self-report measures. J Pers Disord 2004; 18: 555-70.

[63] Parker G, Tupling H, Brown LB. A parental bonding instrument. Br J Med Psychol 1979; 52: 1-10.

[64] Kitamura T, Suzuki T. A validation study of the parental bonding instrument in a Japanese population. Jpn J Psychiatry Neurol 1993a; 47: 29-36.

[65] Kitamura T, Suzuki T. Perceived rearing attitudes and psychiatric morbidity among Japanese adolescents. Jpn J Psychiatry Neurol 1993; 47: 531-5.

[66] Sanders B, Becker-Lausen E. The measurement of psychological maltreatment: Early data on the Child Abuse and Trauma Scale. Child Abuse Negl 1995; 19: 315-23.

[67] Crowne DP, Marlowe D. A new scale of social desirability independent of psychopathology. J Consult Psychol 1960; 24: 349-54.

[68] Kitamura T, Suzuki T. Nihongoban Social Desirability Scale ni tsuite. The Japanese version of the Social Desirability Scale. Jpn J Soc Psychiatry 1986; 9: 173-80.

[69] Schermelleh-Engel1 K, Moosbrugger H, Müller H. Evaluating the fit of structural equation models: tests of significance and descriptive goodness-of-fit measures. Methods Psychol Res Online 2003; 8: $23-74$

[70] Shikai N, Uji M, Chen Z, et al. The role of cop-ing styles and selfefficacy in the development of dysphoric mood among nursing students. J Psychopathol Beh Assess 2007; 29: 241-8.

[71] Furukawa T. Perceived parental rearing: Personality and mental status in Japanese adolescents. J Adolesc 1992; 15: 317-22.

[72] Murphy E, Brewin C, Silka L. The assessment pf parenting using Parental Bonding Instrument: two or three factors? Psychol Med 1997; 27: 333-42.

[73] Parker G. Parental characteristics in relation to depressive disorders. Br J Psychiatry 1997; 134: 138-47.

[74] Plantes MM, Prusoff BA, Brennan J, Parker G. Parental representations of depressed outpatients from a U.S. sample. J Affect Disord 1988; 15: 149-55.

[75] Ray JM. Perceptions of poor maternal care are associated with adolescent depression. J Affect Disord 1995; 34: 95-100.

[76] Rodriguez VB, Bayon C, Franco B, Canas F, Gaell M, Salvador M Parental rearing and intimate relationships in women's depression. Acta Psychiatr Scand 1993; 88: 192-7.

[79] Sato T, Sakado K, Uehara T, et al. Dysfunctional parenting as a risk factor to lifetime depression in a sample of employed Japanese adults: Evidence for the 'affectionless control' hypothesis. Psychol Med 1998; 28: 737-42

[77] Sato T, Sakado K, Uehara T, Nishikawa K, Kasahara Y. Perceived parental styles in a Japanese sample of depressive disorders: A replication outside Western culture. Br J Psychiatry 1997; 170: 173-5.

[78] Sato T, Uehara T, Sakado K, et al. Dysfunctional parenting and a lifetime history of depression in a volunteer sample of Japanese workers. Acta Psychiatr Scand 1997; 96: 306-10.

[80] Uehara T, Sato T, Sakado K, Someya T. Parental Bonding Instrument and the Inventory to Diagnose Depression Lifetime version in a volunteer sample of Japanese workers. Depress Anxiety 1998; 8: 65-70. 